\title{
Self-Expression in Speech Acts
}

\author{
Maciej Witek*
}

Received: 23 July 2019 / Revised: 9 September 2020 / Accepted: 12 December 2020

Abstract: My aim in this paper is to examine Mitchell S. Green's notion of self-expression and the role it plays in his model of illocutionary communication. The paper is organized into three parts. In Section 2, after discussing Green's notions of illocutionary speaker meaning and self-expression, I consider the contribution that selfexpression makes to the mechanisms of intentional communication; in particular, I introduce the notion of proto-illocutionary speaker meaning and argue that it is necessary to account for acts overtly showing general commitments that are not 'marked' as being specific to one or another illocutionary force. In Section 3, I focus on Green's account of expressive norms and argue that their function is to stabilize rather than constitute the structure of illocutionary signalling systems; moreover, I examine critically Green's idea according to which expressive norms enable us to indicate the force of our speech acts and suggest that they play a key role in the mechanisms for epistemic vigilance. Finally, in Section 4, I elaborate on the idea of discourse-constituted thoughts - or, in other words, thoughts that exist in virtue of being expressed in making certain conversation-bound speech acts - and use it to develop a more comprehensive model of the expressive dimension of speech acts.

* University of Szczecin

(iD) https://orcid.org/0000-0002-0462-1678

Institute of Philosophy and Cognitive Science, University of Szczecin ul. Krakowska 71-79, 71-017 Szczecin, Poland.

\maciej.witek@usz.edu.pl

() The Author. Journal compilation (C) The Editorial Board, Organon F.

This article is distributed under the terms of the Creative Commons Attribution-NonCommercial 4.0 International Public License (CC BY-NC 4.0). 
Keywords: Expressive norms; illocutionary communication; self-expression; speaker meaning; speech acts.

\section{Introduction}

In this paper I examine Mitchell S. Green's (2007; 2009; 2016) notion of self-expression and the role it plays in his theorizing about illocutionary communication. In particular, my focus is on expressive speech acts: assertions, requests, promises, apologies, congratulations, and other illocutions "for which Moorean absurdity is possible" (Green 2009, 155). According to Green, a characteristic feature of expressive speech acts is that they "are designed to provide propositional-knowledge-enabling evidence of psychological states" (Ibid., 146); in other words, expressive speech acts are designed to signal and show introspectively available states that are specified in their sincerity conditions: assertions are designed to express beliefs, requests desires, promises intentions, apologies regrets, and so on. Green also claims that the mechanism which vouchsafes the stability of the abovementioned signaling systems - i.e., systems comprised of illocutionary acts and the psychological states they express - makes an essential use of the socalled sincerity or expressive norms; roughly speaking, the norms in question constitute the structure of the social environment in which expressive speech acts function as handicaps: signals difficult to fake in virtue of being costly to produce (Ibid., 150-151).

The paper is organized into three parts. In Section 2, I begin with discussing Green's notions of illocutionary speaker meaning (Green 2007, 74) and self-expression (Ibid., 43) and, next, move to considering the various roles of self-expression in intentional communication. In Section 3, after discussing Green's model of expressive speech acts as handicaps, I argue that the function of what Green calls expressive norms is to stabilize the structure of illocutionary signalling systems rather to enable us to indicate the force of our speech acts; in other words, I cast doubt on the idea that expressive norms enable us to indicate "how what is said is to be taken and what would count as an appropriate reply" (2009, 160), and suggest that they form an essential part of the mechanisms for epistemic vigilance. Finally, in Section 4, I distinguish between two types of self-expression: $(i)$ 
expressing with the thinking-to-speaking direction of influence and (ii) expressing with the speaking-to-thinking direction of influence or, in other words, between ( $i$ ) expressing discourse-independent thoughts and (ii) expressing discourse-dependent thoughts. I argue that the notion of discourseconstituted or discourse-dependent thoughts - together with the corresponding idea of expressing with the speaking-to-thinking direction of influence - enables us to arrive at a more comprehensive model of self-expression in illocutionary communication.

\section{Meaning, expressing, and intentional communication}

\subsection{Speaker meaning as a species of signalling}

In "Self-Expression" Mitchell Green (2007) offers a redefinition of the Gricean notion of speaker meaning. The basic idea underlying his model of intentional communication is that "speaker meaning [is] a species of signalling" (Green 2007, 75). More specifically, he uses the conceptual framework of his signalling model of communication to define three notions: factual speaker meaning (Ibid., 67), objectual speaker meaning (Ibid., 68), and illocutionary speaker meaning (Ibid., 74). A central idea behind these concepts is that to speaker-mean an item - a fact, an object, or a commitment, respectively - is to signal and overtly show it: to perform an action intending that in performing it, first, one enables knowledge about the signalled item in an appropriately endowed receiver and, second, makes it manifest that one has this intention. In the remaining part of this paper I use the term 'intentional communication' to refer to the practice that consists in performing acts of objectual, factual, and illocutionary speaker meaning; in Subsection 2.3 below, however, I introduce the notion of proto-illocutionary speaker meaning and argue that it is necessary to account for those forms of intentional communication that cannot be explained as cases of objectual, factual or illocutionary speaker meaning.

According to Green, a signal is "any feature of an entity that conveys information (including misinformation) and that was designed for its ability to convey that information." (Green 2007, 49) For instance, bright coloration in a poisonous tree frog signals potential predators that it is noxious if 
eaten; an alarm call produced by a vervet monkey signals to its conspecifics the presence of a predator in their vicinity; my scowl signals to my interlocutors that I'm anxious or angry, and my smile signals that I'm happy.

Veracious or sincere signals constitute special cases of showing. Generally speaking, to show an item is to provide evidence for it and thereby enable knowledge of what is shown in appropriately endowed observers. I can use calculations to show that there is a black hole in the center of the Milky Way; I can roll my shoulders up to show my mosquito bites and, by the same token, to make them perceptible; and I can draw a picture of my new house to enable my friends to know how it looks. In sum-Green (2007, 47-49; 2009, 141-142) argues - there are three forms of showing that enable, respectively, propositional, perceptual and qualitative knowledge in appropriately endowed observers.

Consider, for instance, a frog that belongs to a population of frogs whose bright coloration is associated to a high enough degree with their being noxious; according to Green, if the frog does not use Batesian mimicry to escape predation, its bright coloration not only signals, but also shows that the frog is noxious. Consider, by analogy, a population of vervet monkeys producing alarm calls that in a sufficient number of cases correlate with occurrences of predators; a veracious alarm call produced by one of these monkeys, then, both signals and shows the presence of a predator in its vicinity. Finally, taking into account behavioral regularities to be found among humans, my sincere scowl not only signals, but also shows my anger, and my sincere smile both signals and shows that I am happy.

Let us go back to discussing Green's notion of speaker meaning. To speaker mean an item, he claims, is to deliberately and overtly show it. In other words, it is to produce or use a signal with an intention, first, to enable knowledge about the signalled item in an appropriately endowed receiver and, second, to make this intention manifest. Like Grice (1975) and Bach and Harnish (1979), then, Green defines the notion of speaker meaning in terms of overt and self-referential intentions. ${ }^{1}$ Unlike Grice and his fol-

\footnotetext{
1 A characteristic feature of a self-referential intention is that its content involves reference to the intention whose content it is (Green 2007, 66n); some self-referential intentions are reflexive in that their fulfilment consists in their recognition (Bach
} 
lowers, however, he claims that speaker meaning involves no audience-directed intentions. In particular, it does not require intentions to produce effects on others, e.g., an intention to get the audience to form certain beliefs or other propositional attitudes. Manifesting or showing an item - an external fact or object, a psychological state, a piece of information, and so onconsists in making it publicly accessible; it can, but does not necessarily have to, involve bringing about a corresponding change in the cognitive state of the receiver. According to Green "it's necessary and sufficient for speaker meaning that one overtly show something, or overtly show that something is so, or overtly show one's commitment to a content in a certain way." (Green 2007, 46)

In short, what constitutes the force and content of an act of speaker meaning construed as a species of signalling is not the Gricean audiencedirected intention with which it is made - if there is any - but what can be called the communicating agent's signalling intention: her overt and selfreferential intention to manifest or show an actual fact, a real object, or her commitment to a propositional content. In putting things this way, Green rejects what Lepore and Stone call prospective intentionalism: "the view that the meaning of an utterance derives from the changes that the speaker plans for the utterance to bring about in the conversation." (Lepore and Stone 2015,200$)^{2}$ At the same time, he integrates intentional communication - that consists in producing and interpreting acts of speaker meaninginto a broad and comprehensive picture of communication provided by the signalling model (Green 2007; 2009) recently enriched with his conception of organic meaning (Green 2017; 2019b). According to this model, "[s]ignals constitute what [Green calls] organic meaning, which overlaps with natural

and Harnish 1979). As Green $(2007,68)$ notes, some authors cast doubt on the possibility of self-referential propositional attitudes. For instance, Mark Siebel (2003) argues that self-referential intentions in general and reflexive intentions in particular are unthinkable mental representations. For an attempt to resist Siebel's scepticism about self-referential intentions, see (Witek 2009); for a critical discussion of Witek's defence of the psychological reality of reflexive intentions, see (Siebel 2020, 106-107). 2 For a discussion of Lepore and Stone's criticism of prospective intentionalism, see (Witek 2016). 
meaning while including speaker meaning as a special case." (Green 2017, 317)

To speaker mean an object is to overtly and deliberately show it or, in other words, to make it perceptible to or at least accessible to the attention of appropriately situated observers; to factually speaker mean that $P$ is to overtly and deliberately show that $P$ or, in other words, to show the fact that $P$; finally, to speaker mean that $P \varphi$-ly-i.e., to perform an act of illocutionary speaker meaning - is to overtly show one's commitment to the proposition $P$ under force $\varphi$ or, in other words, overtly show one's $\varphi$-specific commitment to the proposition that $P$. It is instructive to stress that showing, unlike signalling, is a 'success' notion: one can only show actual facts and real objects (Green 2007, 49); a faked signal only appears to show what it signals. For this reason, both objectual and factual speaker meaning are factive. Illocutionary speaker meaning, by contrast, is not factive: one can illocutionary speaker mean that $P$-for example, one can mean that $P$ as an assertion - even though one lies or is mistaken in believing that $P$. The point is that what the speaker shows in asserting that $P$ is not the fact that $P$, but her force-specific commitment to the proposition that $P .{ }^{3}$ Of course in issuing an utterance that takes effect as an assertion that $P$ one can, provided it is true that $P$, not only show one's commitment to the proposition that $P$, but also show the fact that $P$. It is important to keep in mind, however, that the utterance under discussion constitutes two different though closely related acts: as an act of factual speaker meaning, it shows the fact that $P$; as an act of illocutionary speaker meaning, it shows the speaker's force-specific commitment to the proposition that $P$.

\subsection{Self-expression as a species of signalling}

Green uses the conceptual framework of his signalling model of communication to define the following notion of self-expression:

(S-E) "Where $\mathrm{A}$ is an agent and $\mathrm{B}$ a cognitive, affective, or experiential state of a sort to which $A$ can have introspective access, A expresses her B if and only if $\mathrm{A}$ is in state $\mathrm{B}$, and some action

3 For Green $(2007,102-103)$, one cannot lie that $P$ without asserting that $P$, i.e., without showing one's commitment to the proposition that $P$. 
or behaviour of A's both shows and signals her B." (Green 2007, $43)^{4}$

A blush on my face betrays my embarrassment. It shows my affective state or, in other words, makes it cognitively accessible or even perceptible to appropriately competent observers: it is a cue that can be used by others to recognize my current psychological state. Nevertheless, it does not signal my embarrassment: the proper function of a blush on one's face -i.e., its proper purpose understood as the effect for the production of which it has been selected for (Millikan 1984 and 2004) - is not to convey information about one's affective state; rather, it seems to be a by-product of one's "flight or fight" response to an embarrassing situation, which results from dilating one's blood vessels to increase the quantity of oxygen delivered to one's muscle. ${ }^{5}$ In short, my blushing shows but do not express my embarrassment. By contrast, a characteristic smile on my face, if sincere, both shows and signals my friendly attitude towards my interlocutor; it is natural to assume, namely, that friendly smiles have been selected or designed for their ability to convey friendly attitudes. For this reason, one's sincere smile can be said to express one's friendly attitude. It is instructive to note, however, that insincere friendly smiles fail to express what they signal. Like showing, expressing is a 'success' term. My sincere scowl express my anger. My insincere scowl, by contrast, only appears or purports to express it.

\subsection{Self-expression in intentional communication}

Self-expression construed as sincere signalling of one's own introspectible mental states plays at least three roles in intentional communication. First, (i) in some cases what the communicating agent expresses is identical to

4 It is worth noting - following one of the reviewers - that in one of his recent papers Green (2019a) offers a revised definition of self-expression in which he drops the "of a sort to which A can have introspective access" requirement. However, a detailed discussion of this revision goes beyond the scope of the present paper.

5 As Green notes, however, "[a]dvances in the evolutionary biology of facial expression might show (...) that blushing did evolve to signal embarrassment" (2007, 27 ) and, by the same token, show that a blush on one's face is a signal; for references to recent works on blushing, see (Green 2019a).

Organon F 28 (2) 2021: 326-359 
what she speaker-means. Second, (ii) no matter whether it is speaker-meant or not, what is expressed may contribute to the determination of what is said. Third, (iii) many speech acts have a characteristic expressive dimensione.g., sincere assertions express beliefs, sincere promises intentions, and sincere apologies regrets - which plays a role in illocutionary communication.

(i) Let us focus, first, on cases in which what one speaker-means coincides with what one expresses (Green 2007, 84). For the sake of illustration, let us consider what Tim Wharton $(2003,456 \mathrm{n})$ calls deliberately shown natural behaviours: openly displayed natural manifestations - signs or signals - of what is within. For instance, my involuntary shiver means naturally that I'm cold. It is instructive to stress, however, that it is a cue or sign rather than a signal, since the proper function of one's shiver is to "generate heat by rapid muscle movement" (Wharton 2003, 469) rather than to convey that one is cold. By contrast, my scowl is a signal whose function-i.e., the effect for the production of which scowls qua signals were selected for - is to convey that I'm angry. However, even if produced in a normal way - that is to say, if produced spontaneously as direct manifestations of what one feels - shivers, scowls, and other natural behaviours can be overtly used to communicate what they naturally signify or signal. More specifically, I can openly display my shiver to make it manifest that I'm cold; by analogy, I can deliberately demonstrate my scowl to overtly show my anger. In general, one can openly and deliberately show one's feelings by - as Wharton puts it - "making no attempt to conceal a spontaneouslyproduced natural sign or signal in circumstances where it is obvious to both communicator and audience that she could have taken steps to conceal them." (Wharton 2012, 575) In a similar vein, Green argues that automatically produced natural manifestations of our affective states can be regarded as intentional signals - i.e., as instances of intentional communication-provided they "are not inhibited but, (a) at the time they are manifested, could have been, and (b) we refrain from inhabiting them for a reason". (Green 2007, 96) Consider, for instance, my friend who deliberately maintains her spontaneous scowl or, in other words, purposefully makes no attempt to inhibit it. In doing this, she openly and intentionally shows her anger. In my view, she can also be regarded as overtly showing her anger, provided she makes clear the intention to show it. 
In producing a sincere overt scowl, then, I speaker-mean my anger or the fact that I'm angry; in other words, I perform an act of objectual or factual speaker meaning respectively. At the same time I express my anger. Therefore, in deliberately and overtly displaying my scowl I speaker-mean and express one and the same thing or state. What is more, my act of intentional communication builds and draws on my act of self-expression and, as a result, what I speaker-mean is directly determined by what I express: to express one's own introspectible state is to signal and show it; ${ }^{6}$ to speaker-mean what one expresses it suffices to signal and show it overtly. "Overt self-expression (...) is a form of speaker meaning." (Green 2007, 82)

In short, sincere and overtly demonstrated natural manifestations of what is within take effect as acts of speaker meaning. Let us have a closer look, however, at non-sincere overt signals of introspectible states which, according to Green (2007, 97-98), should be also regarded as cases of speaker meaning. In particular, let us consider whether sincere and non-sincere overt scowls can be accounted for in a uniform way. Recall that in producing a sincere overt scowl, I perform an act of factual or objectual speaker meaning; in other words, what I overtly show is either the fact that I am angry or my being angry, respectively. My non-sincere, overt scowl, by contrast, only appears or purports to show my anger and, for this reason, cannot be regarded as an act of objectual or factual speaker meaning (by the same token, it cannot be regarded as expressing my anger). Green (2007, 97-98) claims, however, that in making a non-sincere, though overt scowl I speakermean my anger. How is it possible? To answer this question, it suffices to assume that what my non-sincere scowl overtly shows is not my anger, but my commitment to my being angry. In this respect, my non-sincere scowl can be likened to an act of illocutionary speaker meaning. In the case of the latter, however, what we show is a force-specific commitment, e.g., the commitment characteristic of assertions, the commitment characteristic of presumptions, and so on. In the case of my non-sincere, overt scowl, by contrast, what I show is a general commitment that is not 'marked' as being specific to one or another illocutionary force. For this reason, I propose to describe it as a case of proto-illocutionary speaker meaning: like illocutionary

${ }^{6}$ See Green's characterisation of self-expression discussed in Subsection 2.2 above. 
speaker meaning, it shows my commitment to a certain object or fact; the commitment thereby shown, however, is not force-specific. ${ }^{7}$

It remains to be considered whether $(a)$ sincere and non-sincere overt scowls represent two distinct subcategories of speaker meaning - that is, factual and proto-illocutionary, respectively - or, rather, (b) should be accounted for in a uniform way as instances of proto-illocutionary communication. Although I am more sympathetic to hypothesis (b), I think that its justification requires empirical studies on overt self-expression. It should be examined, for instance, whether $(a)$ only non-sincere manifestations of affective states have a normative dimension, whereas their sincere counterparts are cases of merely factual speaker meaning, or, rather, (b) both sincere and non-sincere overt manifestations give rise to normative expectations on the part of the audience. ${ }^{8}$ My hypothesis is that the latter is the case: in my view, there are no independent reasons for assuming that the difference between sincere and non-sincere overt manifestations corresponds to the distinction between acts of merely factual speaker meaning (i.e., cases of showing facts but not commitments) and acts of merely commitmentincurring speaker meaning (i.e., cases of showing commitments but not facts).

( $i$ i) Let us focus on the role of self-expression in determining the intuitive and occasion-sensitive truth-conditional content of an utterance, which can be called, following the Gricean tradition in pragmatics, its impliciture (Bach 1994), explicature (Wilson and Sperber 2012) or, simply, what is said (Recanati 2004).

As Wharton observes, our speech acts are accompanied by or involve the use of a number of paralinguistic indicators - such as facial expressions, intonation patterns, gestures, and so on - that function as signals conveying information about what we feel while speaking; they make up natural codes

$7 \quad$ It is instructive to note that acts of proto-illocutionary speaker meaning are akin to what Green $(2007,100-101)$ calls "non-conventional, non-conversational implicatures."

8 As one of the reviewers rightly notes, one can take the sincere and overt cases to be both factual and commitment-incurring acts of speaker meaning and at the same time describe non-sincere overt cases as commitment-incurring only. In my view, however, this option is in line with hypothesis $(b)$. 
or natural signalling systems that enable us to show and express our affective states. At the same time they may contribute to the determination of what we say or, in other words, play a role in constructing the occasionspecific truth-conditional contents of our utterances. Consider-following Wharton $(2003,463)$ - a situation in which Jack utters the following words in a furious tone:

(1) I am angry.

and frowns sternly in an overt manner. The angry tone of his voice and his frown show and express his affective state. What is more, the furiousness of his voice - and the same can be said about the sternness of his frowncorresponds to and indicates the intensity of his anger. Independently of whether it is speaker-meant or not, the expressed content contributes to the determination of what Jack says or, in other words, to the occasion-specific truth-conditional content of his utterance. It is instructive to note, namely, that sentence (1) contains a token of 'angry', whose interpretation requires establishing the type and degree of Jack's anger. To arrive at such an interpretation, Jack's interlocutor makes use of "her ability to discriminate among tiny variations in his facial expression and tone of voice" (Wharton 2003,464 ), that is to say, her ability to read natural manifestations of Jack's anger. ${ }^{9}$ As Wharton puts it:

9 One of the reviewers is critical of the above-presented discussion of the 'I am angry' example and claims that the predicate 'angry' does not behave in the way described by Wharton. To support his or her opinion, the reviewer points out that, first, we can refer to two people - one moderately angry and the other very angryand say:

(2) Both of those two people are angry.

Second, he or she claims that language interpretation is on the whole digital, while reading facial expression is analogue. Even though I agree with the two points made by the reviewer, I do not think that they speak against Wharton's analysis of the case under discussion. First, viewed from the perspective of the post-Gricean truthconditional pragmatics (Carston 2002; Recanati 2004; Sperber and Wilson 2012; for a critical overview see Chapter 1 of Jaszczolt 2016), the two different tokens of 'angry' - one occurring in the utterance of (2) and the other occurring in Jack's utterance of (1) - encode the same concept ANGRY, which provides an input to a pragmatic process of modulation. In the two cases under discussion, the process gives

Organon F 28 (2) 2021: 326-359 
the paralinguistic indicators Jack uses overtly will play a role in Lily's determining not only what - to return to Grice's terminology-he has meant ${ }_{N N}$, but also the proposition she takes Jack to be expressing (or what he has said). 'Angry' is a degree term, and the truth conditions of Jack's utterance of 'I am angry' will vary according to the type or degree of anger he intends to communicate (and hence reflects in his paralinguistic behaviour). (Wharton 2003,463$)$

(iii) Illocutionary acts "for which Moorean absurdity is possible" (Green $2009,155)$ have a characteristic expressive dimension: assertions are naturally taken to express beliefs, requests desires, promises intentions, apologies regrets, and so on. According to Green, the verb 'express' used in the preceding sentence should be read as 'show and signal one's own introspectible state'; in other words, the common-sense idea of expressing thoughts with words can be adequately elaborated and theoretically refined along the lines of his model of self-expression.

rise to the construction of two different occasion-specific or ad hoc concepts ANGRY* and ANGRY**, respectively. According to the relevance-theoretic perspective adopted by Wharton (2003; 2012; see also Wilson and Wharton 2006), the concept ANGRY* can be characterised by its inferential role (Wilson and Sperber 2012: 22), i.e., by reference to the logical and conversational implications derivable from the utterance of (2) that make it a relevant ostensive stimulus (see Ibid., 107-115). It can also be argued that the information carried by natural signals produced by Jack- e.g., a certain prosodic pattern and facial expression - plays a role in the context-sensitive process that takes the linguistically encoded concept ANGRY as its input and gives the modulated concept ANGRY** as its output. In other words, it can be argued that the information plays a role in constructing the explicature of Jack's speech act: the occasion-sensitive proposition that results from enriching the logical form of his utterance and interprets the thought he intends to communicate. Second, one can reconcile the idea of language interpretation as a digital process with the post-Gricean idea of pragmatically modulated concepts. Linguistic interpretation is digital in that it delivers encoded concepts that function as linguistically determined and stable meanings of lexical items; the concepts so delivered, however, undergoes the pragmatic process of modulation that gives rise to a plethora or even continuum of occasion-specific meanings. It is instructive to add that the modulating processes under discussion can make use of the information carried by natural signals that constitute analogue codes. 
Generally speaking, sincere expressive speech acts both signal and show speakers' current psychological states. In this respect, then, they are akin to sincere and overt natural manifestations of psychological states: my sincere assertion that $P$ and my sincere scowl express my belief that $P$ and my anger, respectively; what is more, my insincere assertion that $P$ only appears to express my belief that $P$, and my non-sincere, overt scowl only appears to express my anger. Recall, however, that in deliberately and overtly displaying my scowl, I speaker-mean what my scowl expresses; in other words, what is speaker-meant is directly determined by what is expressed. In the case of expressive speech acts, by contrast, speakers do not mean what their acts express. In asserting that $P$, for instance, I speaker-mean that $P$ assertorically and express my belief that $P$ (more specifically, I express my belief that $P$ as justified in a way appropriate for knowledge; for a discussion of this idea, see Section 3 below). In short, it is relatively easy to identify and describe the role of self-expression in acts of what I dubbed proto-illocutionary communication: what is expressed directly determines what is meant. It is not so easy, however, to identify the role of self-expression in illocutionary communication. I consider this topic in the next section.

\section{Self-expression in illocutionary signalling systems}

A central idea behind Green's account is that expressive speech acts are designed to show the states that are specified in their sincerity conditions: assertions are designed to show beliefs, directives desires, and promises intentions. Recall, however, that the verb 'express' that occurs in constructions of the form ' $X$ expresses mental state $M S$ ' is factive: according to Green, an asserter "who is not sincere provides good evidence for a belief that she lacks, and thus only appears to show her belief" (Green 2009, 146; the italic is mine-MW). ${ }^{10}$ It remains to be examined, therefore, what stabilizes the illocutionary signalling system that consists of our expressive

10 It is instructive to note that in his more recent definition of expression presented in (Green 2019a), Green drops the requirement that the verb 'to express' is factive. In the present paper, however, I stick to the definition that comes from (Green 2007) and (Green 2009). 
speech acts - e.g., assertions - and the mental states they express. In short, what vouchsafes the reliability of speech acts understood as expressing signals?

To answer this question, Green argues that expressive speech acts in general and assertions in particular are handicaps: signals "that can only be faked with great difficulty as a result of being costly to produce." (Green 2009, 150-151) For instance, a male peacock's tails, when produced and maintained in a predatory environment, functions as a reliable signal of its owner's fitness. What vouchsafes its reliability is the fact that it is a handicap: growing and carrying a long tail costs extra calories; what is more, long and colourful feathers makes their owner slower and easier for predators to spot and catch. The crucial point, however, is that in producing and maintaining a long tail, a peacock who lives in a predatory environment incurs the cost of closing off the option of not being sufficiently fit without exposure to the risk of being easily hunted and killed; in other words, peacocks whose trains are faked signals of their fitness incur the cost of being exposed to an unusually high risk of losing life. By analogy, a speaker who asserts that $P$ incurs the cost of closing off the option of not having the belief that $P$ without exposure to the risk of being spotted by a social 'predator': an epistemically vigilant (Sperber et al. 2010) agent who, after recognising the speaker's insincerity, will reproach or even punish her and, as a result, compromise her reputation as a credible social partner. As speakers we put a lot of effort into creating and maintaining our image of ourselves as reliable and credible persons. ${ }^{11}$ In performing insincere assertion, then, we expose ourselves to or at least increase the risk of compromising the opinion others have on us. ${ }^{12}$

11 In (Witek 2019d) I have argued that in theorising about the normative aspect of illocutionary dynamics we should distinguish between perlocutionary and illocutionary credibility: one's power to "produce certain consequential effects upon the feelings, thoughts, or actions of the audience" (Austin 1975, 101) and one's collectively agreed authority to bring about changes in the domain of normative facts "such as attributions of rights, obligations, entitlements, commitments." (Sbisà 2002, 434) For the present purposes, however, it suffices to use the general notion of credibility. 12 As one the reviewers has noted, we also incur the risk of a loss of credibility when we make sincere assertions based on insufficient evidence. 
In short, in virtue of being handicaps our expressive speech acts are reliable indicators of our current psychological states: beliefs, desires, intentions, regrets, and so on. It is instructive to note, however, that signals function as handicaps only if produced and interpreted in a certain environment. For instance, a peacock's train is a handicap only in a predatory environment. By analogy, expressive speech acts are handicaps because they are issued and interpreted in a normative environment: a social context the structure of which is constituted by the so-called sincerity or expressive norms and the normative expectations they give rise to. According to Green $(2009,154)$, the general form of expressive norms is given by the following schema:

(EN) One who produces $\mathrm{S}$ is to be in condition $\mathrm{C}$; otherwise she is subject to a loss of credibility.

For example, the practice of making assertions is governed by the following expressive norm:

(AN) One who asserts that $P$ is to believe that $P$; otherwise she is subject to a loss of credibility.

When performed in an appropriate normative environment, then, expressive illocutionary acts can be regarded as reliable indicators of what is within. It is difficult to fake them because of the limitations put on by expressive norms of the (EN) form.

Green's idea of illocutionary acts as veracious signals of what is within gives rise to a number of questions. One can ask, first, $\left(Q_{1}\right)$ how is it possible for an illocutionary act-or, in other words, for the use of illocutionary force - to show and express what is within. Second, it is worth considering $\left(\mathrm{Q}_{2}\right)$ what determines the correlation between types of illocutionary acts and types of expressed psychological states; in other words, in virtue of what assertions are associated with beliefs, requests with desires, promises with intentions, and so on. Third, one can ask $\left(\mathrm{Q}_{3}\right)$ what is the role that self-expression plays in illocutionary communication construed as a variant of intentional communication.

To answer question $\left(\mathrm{Q}_{1}\right)$, Green (2009) uses his model of expressive speech acts as handicaps, according to which illocutionary acts are reliable indicators of what is within. A speaker who performs an expressive illocutionary act, 
then, produces strong enough evidence that she has an appropriate psychological state. For instance, in asserting that $P$, she produces a signal that provides strong enough evidence that she believes that $P$. If, in addition, her assertion is sincere, it enables propositional knowledge about her belief in her interlocutors; in short, it shows and thereby express her belief that $P$.

Let us focus on question $\left(\mathrm{Q}_{2}\right)$, which, as far as I know, is not directly addressed by Green. At first sight, it seems to have an obvious answer. One might think, namely, that the signification relation between illocutionary acts and what they express is determined or fixed by expressive norms of the (EN) form; in other words, expressive norms determine the structure of illocutionary signalling system. For instance, assertions correlate with beliefs - or, more specifically, one's assertion that $P$ signals one's belief that $P$-in virtue of the constraints imposed by the norm (AS). In my view, however, expressive norms presuppose rather than determine the signification relations that hold between expressive speech acts and expressed psychological states; that is to say, their function is to stabilize rather than constitute the structure of illocutionary signalling systems.

One way to answer question $\left(\mathrm{Q}_{2}\right)$, I think, is to adopt Millikan's (1984; 2004; 2005; cf. Witek 2015a; 2015b) teleosemantic theory. ${ }^{13}$ Elsewhere (Witek 2019b), I have argued that the signification relations that hold between speech acts and psychological states - e.g., between assertions and beliefs, requests and desires, and so on - are to be analysed in terms of Normal conditions for proper functioning of expressing speech acts construed as cooperative intentional signs in Millikan's (2004) sense; cooperative intentional signs, in turn, can be likened to signals in Green's sense:

13 One of the reviewers suggests that Millikan's teleosemantic framework might be used to address question $\left(\mathrm{Q}_{1}\right)$, too. I am very sympathetic to this suggestion. As a matter of fact, elsewhere I have argued that the "capacity of speech acts to express psychological states (...) can be accounted for in terms of [Millikanian] speaker-hearer conventional patterns and the role they play in coordinating joint actions. The normativity of sincerity [or expressive] rules, in turn, can be explained in terms of Normal conditions for proper functioning of illocutionary acts qua cooperative intentional signs." (Witek 2019b: 91) A detailed discussion of this topic, however, goes beyond the scope of the present paper. 
items that convey information (including misinformation) and have been designed for their ability to convey that information. Roughly speaking, the fact that one's assertion is sincere in accordance with the relevant signification relation - that can be called, following David Lewis (2002), the signaller's contingency plan -is a Normal condition for its proper functioning as an expressive signal, where the proper function of one's assertion qua assertion is to contribute to the achievement of what I call mental coordination: a preferred correspondence between the interacting agents' individual representations of their shared mental states. A detailed discussion of this proposal goes beyond the scope of the present paper. ${ }^{14}$ For the current purposes it suffices to note that the signification relations holding between sincere expressive illocutionary acts and what they express constitute the Normal condition under which the acts can contribute to the achievement of mental coordination between the conversing agents, where 'Normal' is to be read along the Millikanian lines as standing for conditions to which a given device or trait has been adapted rather than for statistically normal conditions in which it functions. In short, the sincerity of a speech act constitutes the Normal condition for its functioning as a devise for establishing mental coordination.

Finally, let us address question $\left(\mathrm{Q}_{3}\right)$ and consider the role that selfexpression plays in illocutionary communication. Unlike acts of proto-illocutionary communication, speech acts do not speaker-mean what they express. Therefore, their expressive dimension does not play a direct role in the determination of their communicated content. Green's proposal is that the function of self-expression in illocutionary acts qua illocutionary acts is to help indicate the force with which the speaker says what she does. He claims:

Holding fixed what is said, expressive norms enable us to indicate how what is said is to be taken and what would count as an appropriate reply. Such norms enable us to do that by enabling us to show the psychological state (belief, acceptance, belief as justified, etc.) from which the conversational contribution flows. One could also report the psychological state from which the

14 For a discussion of the idea of mental coordination, see Witek 2019b. 
contribution flows ('I believe that p', etc.), but for most purposes such explicitness is otiose as compared to the stunning power of speech acts to telegraph our states of mind. (Green 2009, 160)

Let us note, first, that from the perspective of the teleosemantic account of illocutionary signalling systems it would be better to speak of psychological states from which conversational contributions Normally flow. Second, the proposal in question pertains only to sincere speech acts; it can be extended so as to cover cases of non-sincere illocutions by saying that expressive norms enable us to indicate the force of an utterance - i.e., "how what is said is to be taken and what would count as an appropriate reply"-by enabling us to pretend to show the introspectible state that the resulting act is designed to signal. Third, Green's account of the role of self-expression in illocutionary communication seems to be circular: the use of an illocutionary force shows a certain psychological state and thereby indicates how what is said is to be taken; in other words, the force of an utterance indicates itself. ${ }^{15}$

To justify the last point, let us distinguish between the following five items:

(a) the use of force $\varphi$,

(b) the norm by which it is (constitutively) governed,

15 As one of the reviewers points out, one can maintain the view that expressive norms $(i)$ enable speakers to express, and thus show, their psychological states, and (ii) determine what subsequent conversational moves are appropriate, but reject the idea that they do the latter by doing the former. Such a clarified and modified version of Green's account of expressive norms is free from circularity. Another reviewer, by contrast, has his or her doubts whether the circularity charge against Green's account of expressive norms and their role in illocutionary communication is fair; he or she claims, namely, that expressive norms establish the correlation between types of illocutionary acts and types of psychological states, and, as the corollary of this, they enable the speaker to indicate the force of her act by enabling her to show the psychological state from which the act flows. In my view, however, the account under discussion is circular: it says that expressive norms of the form "one who uses force $F$ ought to have psychological state $P S$ " enable the speaker to use illocutionary force $F$ to show her psychological state $P S$ and, in this connection, indicate the force of her act; in short, her use of illocutionary force $F$ indicates itself. 
(c) the psychological state that is shown in making the resulting act and the light in which it is shown,

(d) the score-changing potential of the resulting act, i.e., "how what is said is to be taken and what would count as an appropriate reply" (Green 2009, 160),

(e) the $\varphi$-specific commitment overtly shown-i.e., illocutionary speaker-meant - by the speaker.

In my view, Green's proposal under discussion can be reconstructed as follows: $(b)$ enables $(a)$ to indicate $(d)$ by showing $(c)$. In other words, norm (b) plays a key role in the mechanism that enables our uses of force $\varphi$ to show $(c)$, and $(c)$ correlates with $(d)$ and $(e)$; the latter two items, in turnthe score-changing potential of the resulting act and the commitment that the speaker overtly shows - are two complementary descriptions of force $\varphi \cdot{ }^{16}$ In short, the complex mechanism that involves expressive norms, it seems, enables us to use an illocutionary force to indicate itself.

In my view, there is no uniform answer to the question what indicates the force of an utterance or, in other words, what indicates how the utterance is to be taken and what would count as an appropriate reply to it. There are many types of illocutionary force indicative devices, some of which are linguistic (e.g., performative prefixes, grammatical moods, illocutionary adverbs, and so on), whereas other are paralinguistic in Wharton's (2003; 2012) sense. One example of the latter can be a natural code of

16 According to Marina Sbisà, speech acts are "context-changing social actions" (Sbisà 2002, 421) whose types are to be defined by reference to how their performance affects the context of their production; in particular, the force of an illocutionary act is to be defined by reference to how it affects the score of conversation by making certain subsequent conversational moves appropriate or out of order (for a discussion of this idea, see (Witek 2015c) and (Witek 2019c). According to Green (2007, 74), in turn, what determines the force of an act is the speaker's overt intention to show that she is committed to the propositional content she puts forth in a way defined by appropriate conversational norms. In my view, these two descriptions of illocutionary force are complementary: the commitment that is overtly shown by the speaker-i.e., the commitment she speaker-means - can be spelled out in terms of the score-changing potential of her act; for a discussion of this idea, see (Green 2007, 7273), (Green 2009, 157), and (Witek 2019b, 92).

Organon F 28 (2) 2021: 326-359 
prosodic patterns whose function is to indicate or even deliberately show certain aspects of the speaker's psychological states. For instance, a tone of my voice can be a reliable indicator of whether the state that I express in uttering sentence " $P$ " is my belief that $P$ as justified in a way appropriate for knowledge or, rather, my belief that $P$ as backed with some justification; in the former case, my utterance is to be taken as assertion, whereas in the latter case - as a conjecture. ${ }^{17}$ Therefore, at least in some cases self-expression - that, for instance, can employ natural codes - plays a role in indicating the force of an utterance. To acknowledge this, however, is not to say that it plays such a role every time expressive illocutionary acts are made.

What is, then, the relation between $(c)$ the psychological state that is shown in making the resulting act and the light in which it is shown and (e) the $\varphi$-specific commitment overtly shown by the speaker? State $(c)$ is expressed, but not speaker-meant. Commitment (e), by contrast, is speakermeant, but not expressed. There is, however, a norm-based or, provided expressing rules of the (EN) form are constitutive in character, even definitional or constitutive association between $(c)$ and $(e)$. What is the role, therefore, that the expressive dimension of expressive speech acts plays in illocutionary communication?

My tentative answer is that the expressive dimension of speech acts plays a key role in the mechanisms for epistemic vigilance (Sperber et al. 2010): expressive norms enable our interlocutors to recognize sincerity conditions of our speech acts - whose force can be indicated or marked by means of different linguistic and paralinguistic devices, some of which involve forms of self-expression - and thereby to recognize whether we are benevolent and trustworthy speakers. A detailed discussion of this idea, however, goes beyond the scope of the present paper.

\section{Discourse-independent and discourse-constituted thoughts}

Commenting on his characterisation of self-expression (see formula (ES) discussed in Subsection 2.2 above), Green remarks that "A need not have

17 For a discussion of the difference between assertions and conjectures, see (Green 2007, 73) and (Green 2009, 157-158). 
been in state B before her act of self-expression; it is consistent with the account given thus far that what is expressed is somehow constituted by the expressive act" (Green 2007, 43). In other words, the signalling model of communication - as well as the account of self-expression developed within its framework - seems to allow for the existence and expression of what can be called discourse-constituted thoughts. My aim in this section is to elaborate on the idea of mental states that exist in virtue of being expressed - that is to say, to motivate and define the notion of discourseconstituted thoughts - and propose it as a refinement of the conceptual framework of Green's account of the expressive dimension of speech acts. ${ }^{18}$

In particular, I want to draw a distinction between expressing with the thinking-to-speaking direction of influence and expressing with the speaking-to-thinking direction of influence and, next, use it to elaborate on the idea of psychological states from which conversational contributions Normally flow. Roughly speaking, in expressing with the thinking-to-speaking direction of influence we signal and show our discourse-independent thoughts; in expressing with the speaking-to-thinking direction of influence, by contrast, we show and signal our discourse-constituted thoughts. The distinction between these two types of expressing shed light on the issue of sincerity in illocutionary communication. It is difficult to perform insincere speech acts with the thinking-to-speaking direction of influence because of the limits put on by expressive norms; it seems even more difficult to perform insincere speech acts with the speaking-to-thinking direction of influence, since they express discourse-constituted thoughts: mental state whose key aspects exists in virtue of being expressed and as such exemplify what Slobin (1996) calls 'thinking for speaking'.

An example of a discourse-independent or ready-made thought is my belief that Marina is an expert in speech act theory; it is part of my belief box, waiting for an appropriate conversational occasion on which it can be activated and expressed by my telling that Marina is an expert in speech

18 The idea of discourse-constituted thoughts comes from (Jaszczolt and Witek 2018), where it is used to develop a speech act-based model of de se utterances; for a detailed discussion, see (Jaszczolt and Witek 2018, 198-205). A similar idea is discussed by Stina Bäckström (2021), who argues, following Merleau-Ponty, that there are thoughts achieved or accomplished "in expression in the primary sense".

Organon F 28 (2) 2021: 326-359 
act theory. One example of a discourse-constituted thought, in turn, is the Stalnakerian informative presupposition (4) of the speech act made by Peter in uttering sentence (3):

(3) I have to pick up my sister at the airport.

(4) Peter has a sister.

According to Stalnaker, presupposition is "a propositional attitude of the speaker" (Stalnaker 2002, 701): to presuppose that $P$ is to believe (Ibid., 717 ) or accept (Stalnaker 2014, 25) that the proposition that $P$ is part of the common ground of the ongoing conversation. ${ }^{19}$ Therefore, in uttering sentence (3) to make a certain speech act, Peter entertains a thought-a belief or acceptance state - that the proposition expressed by sentence (4) is part of the common ground between him and his audience. Let us assume, however, that prior to the time of this utterance Peter's audience had no idea whether he had a sister and that Peter was aware of their ignorance. Therefore, prior to the time of the utterance under discussion, he had no thoughtno belief and no acceptance state - to the effect that the proposition

${ }^{19}$ One of the reviewers points out that Stalnakerian presuppositions are not beliefs but acceptance states. However, in "Common Ground", a paper published in 2002, Stalnaker takes presuppositions to be "the speaker's beliefs about the common ground" (Stalnaker 2002, 717) and uses the concept of acceptance to define the notion of common ground only. He stipulates that "[a]cceptance (...) is a category of propositional attitudes and methodological stances toward a proposition, a category that includes belief, but also some attitudes (presumption, assumption, acceptance for the purposes of an argument or an inquiry) that contrast with belief, and with each other. To accept a proposition is to treat it as true for some reason." (Ibid., 716) Next, Stalnaker identifies the common ground with "common belief about what is accepted" (Ibid., 716) and argues that this definition is consonant with his original idea of presuppositions as beliefs about the common ground. It is instructive to note, however, that in one of his more recent works Stalnaker claims that "[a]n agent A presupposes that $\phi$ if and only if A accepts (for purposes of the conversation) that it is common ground that $\phi . "$ (Stalnaker 2014, 25) A detailed discussion of the evolution of Stalnaker's views on presuppositions, however, goes beyond the scope of this paper. For the present purposes, it suffices to assume that Stalnakerian presuppositions are propositional attitudes or thoughts of the speaker that can take the form of beliefs or acceptance states. 
expressed by sentence (4) is part of the common ground. Nevertheless, in uttering sentence (3) to make a certain speech act, he signals and shows that he believes or accepts that it is common ground that he has a sister. This presupposition is formed in the course and for the sake of speaking. In other words, it exists in virtue of being expressed. What is more, at the very moment he utters sentence (3), Peter is justified in taking the proposition that he has a sister to be part of the common ground. Viewed from the perspective of Stalnaker's sequential-update model of accommodation, namely, the speech act under discussion is a manifest event - "an event that, when it occurs, is mutually recognized to have occurred" (Stalnaker 2002, 708) - and as such automatically updates the common ground both at the level of what is directly illocuted and, if nobody objects, at the level of what is presupposed. More specifically, if nobody says "But you have no sister!", ${ }^{20}$ the presupposition of Peter's speech act is accommodated, i.e., the proposition expressed by sentence (4) becomes part of the common ground relative to which Peter's direct assertion is interpreted.

I do not want here to discuss the details of Stalnaker's sequential-update model of accommodation and examine its adequacy. ${ }^{21}$ The reason I mention it is that it makes an essential use of the idea of discourse-constituted thought: Peter's presupposition that he has a sister-i.e., his belief or acceptance that it is common ground that he has a sister-is formed in the course and for the sake of speaking; in other words, it exists in virtue of being expressed. As Stalnaker puts it:

[t]here is nothing wrong, in general, with (...) expressing a belief that one would not have if one did not express it. (Stalnaker 2002, 711)

Roughly speaking, then, discourse-constituted thoughts are thoughts whose key aspects are constituted within the progressing discourse (Jaszczolt and Witek 2018). Our discourse-independent thoughts, by

20 Of course more conditions have to be met in order for accommodation to work. For a discussion of this topic, see (Witek 2019a) and (Witek 2019c). For a discussion of blocking the accommodation of faulty presuppositions, see (Langton 2018).

${ }^{21}$ For a critical discussion of Stalnaker's model of presuppositions, see (Witek 2019a).

Organon F 28 (2) 2021: 326-359 
contrast, are in a sense ready-made elements of our mental life, that wait for being activated and expressed. Consistently, we can distinguish two types of expressing: expressing with the thinking-to-speaking direction of influence and expressing with the speaking-to-thinking direction of influence. The former takes place when we reveal our discourse-independent mental states: their semantic and possibly normative properties are in a sense inherited by our words. That is to say, discourse-independent thoughts can be identified with what I call —-following Green (2009, 160) psychological states from which our conversational contributions flow. Expressing with the speaking-to-thinking direction of influence, in turn, is akin to what Slobin (1996) calls thinking for speaking: it takes place when we form certain thoughts for the sake of our current conversational moves and their underlying goals.

Stalnakerian presuppositions are good, but not the only, examples of discourse-constituted thoughts. In my view, many speech acts that necessarily function as conversational moves - let us call them conversationbound acts - are best understood as expressing mental states formed for the sake of current conversational purposes. Before I get to discussing their examples, let me make a general point about the structure of discourseconstituted thoughts and the mechanism whereby they are formed.

The formation of a discourse-constituted thought can be likened to what Lev Vygotsky (1978) called internalization. According to Tomasello (1999) — who in this respect follows Lev Vygotsky — some forms of our thinking result from internalizing socially-constituted patterns of communicative practices; for instance, a child's skills for critical thinking result from internalizing patterns characteristic for those forms of problem-solving dialogues in which participants present alternative perspectives on a certain problem. By analogy, let us consider a situation in which a speaker who is engaged in a certain type of dialogue - e.g., an inquiry, deliberation, persuasion, or negotiation (Walton 2010) - makes a certain illocutionary act that takes effect as a valid or appropriate conversational move. Let us further assume that the move is appropriate only if $\left(c_{1}\right)$ it has a point, i.e., its performance is justified by the current conversational situation the speaker and her audience find themselves in, and $\left(c_{2}\right)$ the speaker, in performing the act, exercises or exploits the role she currently plays in the dialogue: her powers, 
rights, or authority. Conditions $\left(c_{1}\right)$ and $\left(c_{2}\right)$ are necessary, but by no means sufficient for the appropriate or felicitous performance of a conversationbound act. Following John R. Searle (1969, 59-60), we can call them preparatory conditions: they are sine quibus non of the felicitous performance of a conversation-bound act, but do not determine its essential effect. Nevertheless, they offer us an insight into the structure of discourse-constituted thoughts. In my view, in performing a conversation-bound act, the speaker forms and expresses-expresses with the speaking-to-thinking direction of influence - a complex thought whose key aspects correspond to conditions $\left(c_{1}\right)$ and $\left(c_{2}\right)$; in other words, the speaker internalizes and foregrounds the (i) conversation-dependent point behind her act ${ }^{22}$ and the (ii) authority with which it is made.

Let us have a closer look at four illocutionary act types that belong to what Green (2009) calls assertive family: assertions, conjectures, presumptions, and expert pronouncements. In particular, let us focus on their expressive function and consider the nature and structure of the mental states they show. The preliminary results of the analysis are presented below in Table $1{ }^{23}$ Following Green (2009), I assume that the structure of the psychological states expressed by illocutionary acts involves aspectual shapes represented by means of the relevant as-clauses.

22 What I call the conversation-dependent point behind making a conversationbound act should be distinguished from the act's illocutionary point. The conversation-dependent point behind the performance of a given act is to respond to the current conversational situation the speaker and her audience find themselves in. For instance, depending on the conversational context in which it occurs, the point behind saying that Paul pushed John can be to answer a question, explain a previously reported fact, provide evidence or counterevidence for a disputed claim, and so on. The illocutionary point of an act (Searle 1979, 2), in turn, corresponds to the essential condition in Searle's analysis of illocutionary acts (Searle 1969, 60): the illocutionary point of a promise is an undertaking of an obligation by the speaker to do something, whereas the illocutionary point of a request is to attempt to get the hearer to do something.

23 The same pattern can be applied to analysing the expressive dimension of nonassertoric illocutions, e.g. to what Marcin Lewiński (2021) calls action-inducing speech acts whose job is to express conclusions of practical reasoning or, more accurately, conclusions of practical argumentation.

Organon F 28 (2) 2021: 326-359 


\begin{tabular}{ll}
\hline Speech act type & Expressed mental state \\
\hline S's assertion that $P$ & $\begin{array}{l}\text { S's belief that } P \text { as justified in a way appropriate } \\
\text { for knowledge }\end{array}$ \\
\hline S's conjecture that $P$ & S's belief that $P$ as backed with some justification \\
\hline S's presumption that & S's tentative acceptance of the proposition that $P$ \\
$P$ & as $(i)$ formed and expressed to enable the ongoing \\
& argument to proceed despite the absence of con- \\
& clusive or sufficient evidence and $(i i)$ warranted by \\
& virtue of $S$ ' current epistemic and conversational \\
& situation. \\
\hline S's expert pronounce- & S's belief or acceptance that $P$ as $(i)$ formed and \\
ment that $P$ & expressed to address and settle the current ques- \\
& tion under discussion and $(i i)$ warranted by virtue \\
& of $S$ 's authority as an expert in the topic under \\
& discussion.
\end{tabular}

Table 1. Assertive speech acts and what they express

The analysis of the first two illocutionary act types comes from Green (2007). For the sake of the present discussion let us assume that assertions and conjectures are not necessarily conversation-bound acts and, in this connection, express discourse-independent thoughts. Presumptions and expert pronouncements, by contrast, are best understood as conversationbound illocutions that express discourse-constituted thoughts. That is to say, one can specify their preparatory conditions $\left(c_{1}\right)$ and $\left(c_{2}\right)$ and, next, argue that the structure of the mental states the acts express involve two corresponding aspects or aspectual shapes introduced by clauses $(i)$ and $(i i)$, respectively.

For instance, according to preparatory condition $\left(c_{1}\right)$ for presumptions, the conversation-dependent point behind an act of presuming that $P-$ a move made in the course of an argumentative exchange - is to enable the ongoing dialogue to proceed towards its goal despite the absence of sufficient evidence (Lewiński 2017; cf. Witek 2019c); in other words, what motivates or even entitles one of the speakers to presume that $P$ at a certain stage of the argumentative dialogue they are engaged in is the mutually recognized absence of evidence sufficient to settle the current issue under 
discussion. ${ }^{24}$ According to preparatory condition $\left(c_{2}\right)$, in turn, the speaker exploits her accessibility to "the grounding that supports [her] presumption" (Corredor 2017, 282) or, in other words, she exercises her authority to make a felicitous presumption that $\mathrm{P} .{ }^{25}$ The speech act of presuming has its mental counterpart, which can be called mental presumption (Witek 2019c, 3). It is a discourse-constituted thought whose essential aspects result from internalizing and foregrounding the conversation-dependent point behind the act and the authority with which it is made. More specifically, in performing the act of presuming that $P$, the speaker expresses her tentative acceptance of the proposition that $P$ as $(i)$ formed and expressed to enable the ongoing argument to proceed despite the absence of conclusive or sufficient evidence, and as (ii) warranted by virtue of her current epistemic and conversational situation. By analogy, in making an expert pronouncement in the course of an argumentative dialogue, the speaker expresses her belief or acceptance that $P$ as $(i)$ formed and expressed to settle the current question under discussion (Roberts 1996) and as (ii) warranted by virtue of her authority as an expert in the topic under discussion. Generally speaking, the speaker who performs a conversation-bound act for which preparatory conditions $\left(c_{1}\right)$ and $\left(c_{2}\right)$ can be given forms and expresses a discourse-constituted thought-i.e., a mental state that exists in virtue of being expressed - whose structure involves internal counterparts of the $(i)$ conversation-dependent point behind the act and the (ii) authority with which it is made. In other words, in forming and expressing the thought, the speaker internalizes and foregrounds the $(i)$ conversational situation her speech act is designed to address and the $(i i)$ conversation-bound perspective on herself that corresponds to her conversational role or authority (Jaszczolt and Witek 2018). The mental state thereby formed is a discourse-constituted

24 The illocutionary point of the act of presuming, in turn, is to transfer the burden of proof from the speaker to the hearer; for a discussion of this topic, see (Walton 2010), (Corredor 2017), (Lewiński 2017), and (Witek 2019c).

25 Elsewhere I have argued that the type of authority required to perform a felicitous presumption is procedure-based, i.e., what makes a speaker entitled to presume that $P$ at a certain stage of an argumentative exchange is the fact that in issuing the act the speaker follows certain procedures of rational inquiry; for a detailed discussion of this topic, see (Witek 2019c, 23-28).

Organon F 28 (2) 2021: 326-359 
thought the expression of which involves the speaking-to-thinking direction of influence.

If the thoughts expressed by conversation-bound acts-presumptions, expert pronouncements, and so on - are discourse-constituted, then the idea of acts-flowing-from-mental-states fails to provide a sufficient basis for a general account of the expressive dimension of speech acts. Only discourseindependent thoughts can be regarded as states from which conversational contributions flow. Discourse-constituted thoughts, by contrast, are formed in the course and for the sake of speaking; more specifically, aspects $(i)$ and (ii) of the speaker's discourse-constituted thought result from internalizing, respectively, the conversation-dependent point behind her act and the authority with which it is made.

Now let us return to discussing the stability of illocutionary signalling systems. Recall that the idea of speech acts as handicaps enables us to account for the expressive dimension of illocutionary communication. When it comes to acts expressing discourse-constituted thoughts, however, the situation becomes more complex. Expressing discourse-independent thought involves a mechanism with the thinking-to-speaking direction of influence; it begins with activating a ready-made thought and moves to signalling it with words. By contrast, expressing discourse-constituted thoughts is a process with the speaking-to-thinking direction of influence; more specifically, it consists in forming a mental state the key aspects of which are constituted in the course and for the sake of speaking (Slobin 1996; cf. Jaszczolt and Witek 2018). In other words, our ability to form discourse-constituted thoughts results from internalising rules, procedures and patterns governing our illocutionary practice.

Recall that in issuing an expert pronouncement, the speaker exercises her current conversational role or illocutionary power of an expert, which is internalised and foregrounded as an aspect of the thought she thereby expresses; what she shows in saying that $P$, namely, is her belief that $P$ as formed by an expert. Of course, in doing this she can be insincere; in other words, she can fail to believe that $P$; but even if she does not have this belief, she still presents the proposition that $P$ as the content of her expert opinion. What is more, this aspect of her thought is constituted in the progressing discourse and results from internalising her agreed status of an expert. 
Consider, by analogy, making a presumption that $P$. In performing this speech act, the speaker shows her tentative acceptance that $P$ as $(i)$ formed and expressed to enable the ongoing argument to proceed despite the absence of conclusive or sufficient evidence, and as (ii) warranted by virtue of her current epistemic and conversational situation. Consider, for instance, an act of presuming A's honesty made in the course of an informal, nonlegal argumentative exchange. The act is felicitous - felicitous in that it succeeds in putting the onus of proof on the addressee who would like to question A's honesty (see Corredor 2017; cf. Lewiński 2017)—provided the speaker is adequately related to A, i.e., she has an appropriate acquaintance with him, knows him personally and meets him more or less regularly or at least has heard a lot of good things about him, and so on. In short, the speaker is supposed to have the required illocutionary power or authority ${ }^{26}$ that enables her to make felicitous presumptions about A's honesty; it is instructive to note, namely, that this authority can be attacked by an $A d$ Hominem, i.e., by saying to the speaker "You know nothing about A". To cut the long story short: in issuing a presumption that $P$, the speaker signals or expresses - expresses with the speaking-to-thinking direction of influence - her current discourse-constituted thought; what is more, it is difficult for her to be insincere in doing this ${ }^{27}$, since showing her tentative acceptance that $P$ as $(i)$ formed and expressed to enable the ongoing argument to proceed, and as (ii) warranted by virtue of her current epistemic situation, is not the same mental state as believing that $P$ : one can entertain the former without having the latter.

26 For a more detailed discussion of this idea, see (Witek 2019c, 23-28).

${ }_{27}$ As one of the reviewers rightly points out, this claim needs more support. He or she asks, for instance, what if a juror says, "Let's presume that A is innocent," and then proceeds to act in such a way as to suggest that he intended no such thing. In my view, the juror's act is an abuse of condition $\Gamma .2$ in John L. Austin's (1975, 1618) sense, according to which the speaker who invokes an accepted procedure to perform a certain speech act is supposed to "conduct [herself] subsequently" in accordance with what the procedure specifies. Nevertheless, it takes effect as a binding presumption in that it succeeds in putting the onus of proof on those who would like to reject the opinion that $\mathrm{A}$ is innocent. What is more, it expresses the juror's tentative acceptance that $\mathrm{A}$ is innocent as formed for the sake of the current conversational purposes no matter whether she believes that $\mathrm{A}$ is innocent or not.

Organon F 28 (2) 2021: 326-359 
In sum, it is difficult to perform insincere speech acts that express discourse-independent thoughts because of the limits put on by expressive norms. Nevertheless, it seems even more difficult to perform insincere speech acts that express discourse-constituted thoughts, since some of their key aspects exist in virtue of being expressed and are formed in the course and for the sake of speaking.

\section{Conclusions}

My aim in this paper has been to examine Green's notion of self-expression and the role it plays in his model of intentional communication. In particular, my focus has been on the expressive dimension of illocutionary acts for which Moorean absurdity is possible. I have proposed a number of ideas and categories and argued that they constitute a natural refinement and extension of the conceptual framework of Green's signalling model of communication.

In Section 2 I have proposed the notion of proto-illocutionary speaker meaning which, together with the corresponding idea of proto-illocutionary communication, seems to be necessary to account for acts that overtly show general rather than force-specific commitments. I have argued, for instance, that in making an overt scowl-no matter whether it is sincere or not-I overtly show my commitment to the proposition that I'm angry, but the commitment $\mathrm{I}$ show is not specific to a particular illocutionary force.

In Section 3 I have focused on Green's model of the expressive dimension of speech acts and the role expressive norms play in illocutionary communication. In particular, I have offered a critical discussion of his idea according to which expressive norms enable us to indicate illocutionary forces of our utterances and suggested that the norms in question should be rather viewed as playing a key role in the mechanisms for epistemic vigilance (Sperber et al. 2010).

Finally, in Section 4, I have distinguished between $(i)$ expressing discourse-independent thoughts and (ii) expressing discourse-constituted thoughts or, in other words, between $(i)$ expressing with the thinking-tospeaking direction of influence and $(i i)$ expressing with the speaking-to- 
thinking direction of influence. Following Jaszczolt and Witek (2018), I have defined discourse-constituted thoughts as mental states whose key aspects are formed in the course and for the sake of speech acts that express them; in other words, discourse-constituted thoughts exist in virtue of being expressed and result from internalising certain discourse parameters-e.g., the role of the speaker, the current question under discussion she addresses, and so on - that characterise the speaker's act. I have also argued that the notion of discourse-constituted thoughts, together with the corresponding category of expressing with the speaking-to-thinking direction of influence, enable us to arrive at a more comprehensive account of the expressive dimension of illocutionary acts.

\section{Acknowledgements}

I am very grateful to Mitchell S. Green for the stimulating discussions we had on the role of self-expression in speech acts. I would also like to thank Marcin Lewiński and two anonymous reviewers for their insightful comments and suggestions that helped me to improve the first draft of this paper.

\section{Funding}

The preparation of this work was supported by the National Science Centre, Poland, through research grant No. 2015/19/B/HS1/03306.

\section{References}

Austin, John L. 1975. How to Do Things with Words. Oxford: The Clarendon Press. https://doi.org/10.1093/acprof:oso/9780198245537.001.0001

Bach, Kent, and Robert M. Harnish. 1979. Linguistic Communication and Speech Acts. Cambridge, Mass.: MIT Press.

Bach, Kent. 1994. "Conversational Impliciture." Mind \&3 Language 9: 124-62. https://doi.org/10.1111/j.1468-0017.1994.tb00220.x

Bäckström, Stina. 2021. "Must Expression Be Instrumental?" Organon F 28 (2): 282-302. https://doi.org/10.31577/orgf.2021.28202

Corredor, Cristina. 2017. "Presumptions in Speech Acts." Argumentation 31: 57389. https://doi.org/10.1007/s10503-017-9425-y

Green, Mitchell. 2007. Self-Expression. Oxford: Oxford University Press. https://doi.org/10.1093/acprof:oso/9780199283781.001.0001 
Green, Michell S. 2009. "Speech Acts, the Handicap Principle and the Expression of Psychological States." Mind \& Language 24 (2): 139-63. https://doi.org/10.1111/j.1468-0017.2008.01357.x

Green, Mitchell S. 2017. "How much Mentality is Needed for Meaning?" In: The Routledge Handbook of Philosophy of Animal Minds, edited by Kristin Andrews, and Jacob Beck, 313-23. London: Routledge.

https://doi.org/10.4324/9781315742250

Green, Mitchell S. 2019a. "From Signaling and Expression to Conversation and Fiction." Grazer Philosophische Studien 96(3): 295-315.

https://doi.org/10.1163/18756735-09603002

Green, Mitchell S. 2019b. "Organic Meaning: An Approach to Communication with Minimal Appeal to Minds." In: Further Advances in Pragmatics and Philosophy: Part 2 Theories and Applications, edited by Alessandro Capone, Marco Carapezza, and Franco Lo Piparo, 211-228. Springer (Perspectives in Pragmatics). https://doi.org/10.1007/978-3-030-00973-1_12

Jaszczolt, Kasia M. 2016. Meaning in Linguistic Interaction. Oxford: Oxford University Press. https://doi.org/10.1093/acprof:oso/9780199602469.001.0001

Jaszczolt, Kasia M., and Maciej Witek. 2018. "Expressing the Self. From Types of De Se to Speech-act Types." In: Expressing the Self. Cultural Diversity 85 Cognitive Universals, edited by Minyao Huang \& Kasia M. Jaszczolt, 187-222. Oxford: Oxford University Press.

https://doi.org/10.1093/oso/9780198786658.003.0010

Langton, Rae. 2018. "Blocking as Counter-Speech." In New Work on Speech Acts, edited by Daniel Fogal, Daniel W. Harris, and Matt Moss, 144-64. Oxford: Oxford University Press. https://doi.org/10.1093/oso/9780198738831.003.0006

Lepore, Ernie, and Matthew Stone. 2015. Imagination and Convention. Distinguishing Grammar and Inference in Language. Oxford: Oxford University Press. https://doi.org/10.1093/acprof:oso/9780198717188.001.0001

Lewiński, Marcin. 2017. "Argumentation Theory Without Presumptions." Argumentation 31: 591-613. https://doi.org/10.1007/s10503-017-9421-2

Lewiński, Marcin, 2021. "Conclusions of Practical Argument: A Speech Act Analysis". Organon F 28 (2): 420-57. https://doi.org/10.31577/orgf.2021.28207

Lewis, David. 2002. Convention: A Philosophical Study. Oxford: Blackwell Publishers. https://doi.org/10.1002/9780470693711

Millikan, Ruth G. 1984. Language, Thought and Other Biological Categories. Cambridge, Mass.: MIT Press.

Millikan, Ruth G. 2004. Varieties of Meaning. Cambridge, Mass.: MIT Press. https://doi.org/10.7551/mitpress/7072.001.0001

Millikan, Ruth G. 2005. Language: A Biological Model. Oxford: Oxford University Press. https://doi.org/10.1093/0199284768.001.0001 
Recanati, Francois. 2004. Literal Meaning. Cambridge: Cambridge University Press. https://doi.org/10.1017/CBO9780511615382

Roberts, Craige. 1996. "Information Structure in Discourse: Towards an Integrated Formal Theory of Pragmatics." OSU Working Papers in Linguistics 49: 91136.

Sbisà, Marina. 2002. "Speech Acts in Context." Language 63 Communication 22:

421-436. https://doi.org/10.1016/S0271-5309(02)00018-6

Searle, John R. 1969. Speech Acts. An Essay in the Philosophy of Language. Cambridge: Cambridge University Press.

https://doi.org/10.1017/CBO9781139173438

Searle, John R. 1979. Expression and Meaning. Studies in the Theory of Speech Acts. Cambridge: Cambridge University Press.

https://doi.org/10.1017/CBO9780511609213

Siebel, Mark. 2003. "Illocutionary Acts and Attitude Expression." Linguistics and Philosophy 26(3): 351-66. https://doi.org/10.1023/A:1024110814662

Siebel, Mark. 2020. "The Belief View of Assertion." In: The Oxford Handbook of Assertion, edited by Sanford Goldberg, 99-118. Oxford: Oxford University Press. https://doi.org/10.1093/oxfordhb/9780190675233.013.4

Slobin, Dan. 1996. "From "thought and language" to "thinking for speaking". In: Rethinking Linguistic Relativity, edited by John J. Gumperz, and Stephen C. Levinson, 70-96. Cambridge: Cambridge University Press.

Sperber, Dan, Fabrice Clément, Christophe Heintz, Olivier Mascaro, Hugo Mercier, Gloria Origgi, and Deirdre Wilson. 2010. "Epistemic Vigilance." Mind \& Language 25(4): 359-93. https://doi.org/10.1111/j.1468-0017.2010.01394.x

Stalnaker, Robert. 2002. "Common Ground." Linguistics and Philosophy 25: 70121. https://doi.org/10.1023/A:1020867916902

Stalnaker, Robert. 2014. Context. Oxford: Oxford University Press. https://doi.org/10.1093/acprof:oso/9780199645169.001.0001

Tomasello, Michael. 1999. The Cultural Origins of Human Cognition. Cambridge, Mass., London, England: Harvard University Press.

https://doi.org/10.2307/j.ctvjsf4jc

Vygotsky, Lev. 1978. Mind in Society. The Development of Higher Psychological Processes. Edited by Michael Cole. Cambridge, Mass.: Harvard University Press.

Walton, Douglas. 2010. "Types of Dialogue and Burden of Proof." In: Computational Models of Argument, edited by Pietro Baroni, Federico Cerutti, Massimiliano Giacomin, and Guillermo R. Simari, 13-24. Amsterdam: IOS Press (Frontiers in Artificial Intelligence and Applications, Vol. 216). https://doi.org/10.3233/978-1-60750-619-5-13 
Wharton, Tim. 2003. "Natural Pragmatics and Natural Codes." Mind \& Language 18(5): 447-77. https://doi.org/10.1111/1468-0017.00237

Wharton, Tim. 2012. "Pragmatics and Prosody." In: The Cambridge Handbook of Pragmatics, edited by Keith Allan, and Kasia M. Jaszczolt, 567-84. Cambridge: Cambridge University Press. https://doi.org/10.1017/CBO9781139022453.031

Wilson, Deirdre, and Dan Sperber. 2012. Meaning and Relevance. Cambridge: Cambridge University Press. https://doi.org/10.1017/CBO9781139028370

Wilson, Deirdre, and Tim Wharton. 2006. "Relevance and prosody." Journal of Pragmatics 38: 1559-579. https://doi.org/10.1016/j.pragma.2005.04.012

Witek, Maciej. 2009. "Scepticism about Reflexive Intentions Refuted." Lodz Papers in Pragmatics 5(1): 69-83. https://doi.org/10.2478/v10016-009-0005-y

Witek, Maciej. 2015a. "An Interactional Account of Illocutionary Practice." Language Sciences 47: 43-55. https://doi.org/10.1016/j.langsci.2014.08.003

Witek, Maciej. 2015b. "Linguistic Underdeterminacy: A View from Speech Act Theory." Journal of Pragmatics 76: 15-29. https://doi.org/10.1016/j.pragma.2014.11.003

Witek, Maciej. 2015c. "Mechanisms of Illocutionary Games." Language 86 Communication 42:11-22. https://doi.org/10.1016/j.langcom.2015.01.007

Witek, Maciej. 2016. "Accommodation and Convention." Polish Journal of Philosophy 10(1): 99-115. https://doi.org/10.5840/pjphil20161016

Witek, Maciej. 2019a. "Accommodation in Linguistic Interaction. On the so-called Triggering Problem." In: In Philosophical Insights into Pragmatics, edited by Piotr Stalmaszczyk, 163-92. Berlin \& Boston: De Gruyter (Philosophical Analysis, Vol. 79). https://doi.org/10.1515/9783110628937-009

Witek, Maciej. 2019b. "Coordination and Norms in Illocutionary Interaction." In: Normativity and Variety of Speech Actions, edited by Maciej Witek and Iwona Witczak-Plisiecka, 66-98. Leiden: Brill (Poznań Studies in the Philosophy of the Sciences and the Humanities, Vol. 112). https://doi.org/10.1163/9789004366527_005

Witek, Maciej. 2019c. "Illocution and Accommodation in the Functioning of Presumptions." Synthese https://doi.org/10.1007/s11229-019-02459-4

Witek, Maciej. 2019d. "The Expressive Dimension and Score-changing Function of Speech Acts from the Evolutionist Point of View." Grazer Philosophische Studien 96(3): 381-98. https://doi.org/10.1163/18756735-09603008 